\title{
(Re)escrevendo roteiros (in)visíveis: a trajetória de mulheres transgênero nas políticas públicas de saúde
}

\section{(Re)writing (in)visible scripts: the trajectory of transgender women in public health policies}

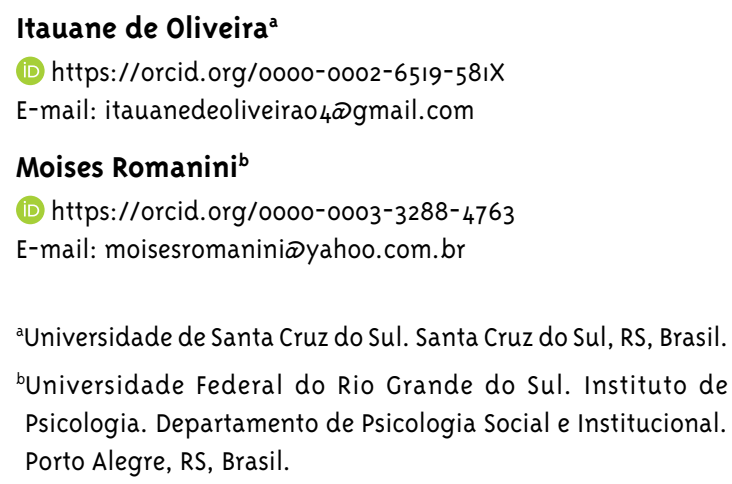
Psicologia. Departamento de Psicologia Social e Institucional. Porto Alegre, RS, Brasil.

\section{Resumo}

Sabe-se que grande parte da população trans está, ainda, sob a égide da marginalização e da exclusão social, encontrando diversas dificuldades no exercício de sua cidadania, incluindo o acesso à saúde. Diante desse contexto, esta pesquisa teve como objetivo compreender a forma como vão se construindo as trajetórias das pessoas transgênero nas políticas públicas de saúde em um município do interior do Rio Grande do Sul. A partir da realização de seis entrevistas narrativas com mulheres trans, buscamos reconstruir os aspectos não indexados de tais relatos, apresentando suas experiências nos serviços de saúde do Sistema Único de Saúde (SUS). Para tanto, utilizamos como norteador das discussões o conceito de tecnologias em saúde, amplamente discutido nas conceituações teóricas de Merhy. Os resultados nos mostram que a existência de políticas públicas, por si só, não garante o acesso da população trans aos serviços de saúde, visto que este, ou mesmo a falta dele, é transversalizado por diferentes fatores. Dificuldades como a falta de preparo dos profissionais de saúde, a patologização da experiência transexual e, principalmente, a falta de acolhimento ainda se fazem presentes. Em detrimento disso, a boa vinculação com os profissionais de saúde contribui de maneira direta para o processo de promoção da saúde dessa população. Palavras-chave: Políticas Públicas de Saúde; Transexualidade; Tecnologias em Saúde.

\section{Correspondência}




\section{Introdução}

It is well known that a large part of the trans people is under the aegis of marginalization and social exclusion, encountering various difficulties in the exercise of their citizenship, including access to health. Faced with this context, this research aimed to understand how trajectories of transgender people are being developed in the public health policies in a city in the countryside of Rio Grande do Sul. From the realization of six narrative interviews with trans women, we aim to reconstruct the not indexed aspects of such narratives, showing their experiences in the Brazilian National Health System (SUS). To this end, we use as guide the discussions on the concept of health technologies, widely discussed in the theoretical concepts of Merhy. The results of this study show that the existence of public policies by itself does not guarantee the access of the trans population to health services, since this access, or lack thereof, is transversalized by different factors. Difficulties such as lack of preparation of health professionals, the pathologizing of transsexual experience and mainly the lack of reception are still present. At the expense of it, the good entailment with health professionals contributes directly to the process of promoting health of this population.

Keywords: Public Health Policies; Transsexuality; Health Technologies.
As políticas públicas podem ser definidas como um conjunto de programas, ações e atividades desenvolvidas pelo Estado com o intuito de assegurar a garantia dos direitos constitucionais inerentes a todos os cidadãos. Assim, a partir da Constituição Federal de 1988, a saúde é estabelecida como um direito inalienável de todo cidadão, devendo ser garantido o acesso universal e integral nos atendimentos realizados pelo Sistema Único de Saúde (SUS). Para tanto, é de extrema importância que as linhas de cuidado ofertadas pelo SUS sejam construídas a partir das reivindicações e necessidades da sociedade civil como um todo, devendo ser levadas em consideração as especificidades próprias de cada segmento populacional. Desse modo, há importantes espaços de controle e participação social, onde é fundamental a participação dos usuários e usuárias do SUS, a fim de garantir a efetivação de uma cogestão das políticas públicas de saúde, pautadas pelas necessidades reais de seus usuários.

Contudo, para Merhy (2012, p. 268), “o SUS se constitui em um campo de práticas sociais, situado sob uma superfície de tensões que o posiciona como lugar permanente de disputas, sociais e históricas", sendo assim um campo atravessado por diferentes questões e temáticas. Para os autores, falar sobre as pluralidades que atravessam o SUS pode ser uma tentativa de visibilizar as forças e tensões constitutivas que o operam, podendo tornar explícito os diferentes territórios de práticas que o compõem. Nessa direção, é de suma importância sinalizar que o Brasil, em toda a sua historicidade, é um país marcado por intensas lutas no âmbito social, sendo palco de grandes enfrentamentos e batalhas contra a desigualdade social. Esta, ainda muito presente em nossos cotidianos, colabora para que haja certa quantificação da vida humana, de modo que determinadas vidas sejam consideradas mais importantes ou dignas de investimento que outras, o que produz um cenário de exclusão e marginalização de determinados grupos populacionais.

Levando em consideração tais apontamentos, sabe-se que grande parte da população trans está, ainda, sob a égide da marginalização e da 
exclusão social, encontrando diversas dificuldades no exercício de sua cidadania. Essas pessoas enfrentam obstáculos no acesso à saúde, educação, moradia, empregabilidade, assistência social, entre outros direitos constitucionais que deveriam ser assegurados a todos os cidadãos. Outro fator que não pode ser ignorado é o alto índice de violência e homicídios ao qual essa população é exposta, o que colabora para que a perspectiva de vida do grupo seja muito inferior à média nacional.

Tendo em vista este cenário, faz-se urgente a efetivação de políticas públicas de saúde que atendam a população trans em sua integralidade, sendo fundamental que tais cuidados sejam pautados por um dos princípios básicos do SUS: a equidade. Um cuidado pautado na equidade deve ter como primazia o respeito pelas demandas específicas de cada usuário, levando em consideração os determinantes sociais que podem incidir de maneira direta na saúde e na qualidade de vida dos sujeitos. Desse modo, é necessário ampliar o debate sobre as questões de gênero no âmbito da saúde, com o intuito de pautar um cuidado para além do padrão biomédico, tendo também como propósito a transposição do imperativo da heteronormatividade, ainda muito presente no cotidiano dos serviços de saúde.

Nessa perspectiva, partindo da ideia de que o acesso por si só não garante a qualidade do cuidado ofertado, pensar o modo como se dá a construção das trajetórias das pessoas trans pelos serviços públicos de saúde pode auxiliar na compreensão dos efeitos que as práticas reproduzidas nesses espaços causam na vida de tais pessoas. 0 cuidado produzido em saúde só acontece mediante o encontro entre o trabalhador de saúde e o usuário, sendo, portanto, caracterizado como um trabalho vivo, em ato, no qual se torna favorável a construção de importantes vínculos terapêuticos. Os atos de saúde, sendo permeados por esse trabalho vivo, só podem ser construídos e efetivados com altos graus de incerteza e, também, de autonomia, tanto por parte dos trabalhadores como por parte dos usuários. Assim, são essas características que ampliam as possibilidades de invenção e construção de novos valores e relações, tendo em vista que há espaço para a invenção e o improviso (Merhy; Feuerwerker, 2009).
Tendo em vista tais considerações, e considerando a potência que pode residir no encontro entre o trabalhador de saúde e o usuário bem como nas tristezas que podem surgir a partir dessa forma de união, este trabalho tem como proposta problematizar, através das narrativas das participantes, os atos de saúde que podem propiciar a expansão ou a captura de novos modos de vida, nesse caso, a vida de pessoas transgênero. Assim, parte-se da ideia de que os vínculos estabelecidos entre as pessoas atendidas e os profissionais que lhes prestam cuidado podem ser determinantes na constituição de uma relação de confiança entre os usuários e os serviços de saúde, e, também, no modo como esses usuários irão se relacionar com as políticas públicas de saúde. Portanto, tratar tais trajetórias sob a ótica de alguns autores de inspiração esquizoanalítica e da psicologia social crítica pode nos auxiliar a problematizar as políticas públicas de saúde e o modo como elas são efetivadas, considerando a forma como repercutem no cotidiano das pessoas que as utilizam.

\section{Percursos metodológicos: um caminho de (des)construção}

No desenvolvimento dessa pesquisa, buscamos nos desconstruir enquanto sujeitos marcados pela identidade de gênero feminina e masculina, para construir um percurso metodológico com as pessoas que compartilharam conosco suas histórias. Com muito cuidado, escutamos essas histórias numa perspectiva crítica da psicologia social, visando não reproduzir discursos de cunho preconceituoso e discriminatório. Desse modo, optamos por construir uma pesquisa inserida no espectro das pesquisas qualitativas, mais especificamente das participativas, um fazer que tem como competência "o mundo da experiência vivida” (Ferigato; Carvalho, 2011, p. 664).

Utilizamos, como forma de acessar as pessoas convidadas a participar de tal estudo, a metodologia denominada bola de neve. Optou-se pelo uso de tal metodologia porque ela pode ser um importante instrumento em casos em que se quer encontrar populações de difícil acesso, como a do presente estudo, ainda mais se considerarmos que estarmos em uma cidade do interior do estado do Rio Grande 
do Sul. Tal metodologia parte de "documentos ou informantes-chaves" (Vinuto, 2014, p. 203), nomeadas como sementes, que auxiliarão o pesquisador a encontrar as pessoas com o perfil necessário para a realização do estudo. Dessa forma, solicita-se que as pessoas indicadas pelas sementes indiquem outras, seguindo, assim, sucessivamente.

Tendo em vista a necessidade de delimitar o perfil das pessoas procuradas para a realização desta pesquisa, definimos os seguintes critérios para inclusão: somente maiores de 18 anos que se dispusessem a participar de forma voluntária. Do mesmo modo, optou-se por ter como primazia a escolha de pessoas que se identificassem publicamente como transgêneros, a fim de evitar qualquer mal-estar ou constrangimento na abordagem dos temas relacionados ao estudo.

Definiu-se que o instrumento a ser utilizado para a construção dos dados seriam as entrevistas narrativas. Segundo Jovchelovitch e Bauer (2003), através das narrativas as pessoas podem rememorar aquilo que vivenciaram, delineando suas experiências em certa sequência de tempo e, assim, encontrando explicações que podem ressignificar o que foi vivenciado. Desse modo, a entrevista narrativa tem por objetivo estimular e encorajar, por meio de um questionamento inicial, o entrevistado a contar uma história sobre algum acontecimento importante da sua vida e do seu contexto pessoal. Seu principal intuito é "reconstruir acontecimentos sociais a partir da perspectiva dos informantes, tão diretamente quanto possível" (Jovchelovitch; Bauer, 2003, p. 93).

Após a transcrição das entrevistas, tal material foi dividido em conteúdo indexado e não indexado. Conforme Jovchelovitch e Bauer (2003, p. 106), as proposições indexadas fazem menção a situações e acontecimentos concretos, que sejam referentes a um lugar e um tempo, enquanto as proposições não indexadas vão além de acontecimentos, expressando "valores, juízos e toda forma de uma generalizada sabedoria de vida". O presente artigo compõe um conteúdo híbrido entre materiais indexados e não indexados, uma vez que as experiências e trajetórias nas políticas públicas de saúde aqui apresentadas trazem, ao mesmo tempo, (1) elementos e situações concretas das histórias de vida dessas mulheres e (2) as apropriações e saberes construídos a partir das experiências vividas. Essas trajetórias foram compreendidas sob a luz de referenciais teóricos pautados na psicologia social crítica e com autores que dialoguem com a perspectiva da esquizoanálise. Mais do que o diálogo estabelecido com os autores e suas teorias, o manuscrito foi enviado às participantes da pesquisa, sendo ofertado um espaço de troca, sugestões e críticas em relação à escrita. Portanto, este texto é resultado de múltiplas “mãos”, que foram escrevendo e reescrevendo essas trajetórias.

Cabe ainda salientar que este estudo não tem como objetivo ocupar o lugar de protagonismo que é, por direito, dos movimentos sociais e militantes LGBT $^{1}$, assumindo o compromisso ético de estar aliado a esses movimentos na luta pelo fim do preconceito e da discriminação de gênero. Também é necessário ressaltar que se compreende que a maior parte da população transgênero ainda se encontra em situação de invisibilidade social, convivendo com maior exposição à violência e à vulnerabilidade social. Contudo, esta pesquisa não tem a pretensão de construir dados sobre essa população, mas com ela, partindo do pressuposto de que o conhecimento científico deve ser construído coletivamente, levando em conta o saber que reside em todos os sujeitos. A pesquisa foi aprovada pelo Comitê de Ética em Pesquisa da Universidade de Santa Cruz do Sul sob CAAE no 70598317.1.0000.5343.

Para preservar a identidade das pessoas entrevistadas, pesquisamos sujeitos que fizeram parte da história de lutas pela garantia de direitos do público LGBT, especialmente pessoas trans, atribuindo esses nomes às participantes. Cabe ressaltar que não limitamos a pesquisa às mulheres, mas no decorrer da pesquisa acabamos nos encontrando com seis mulheres, que compartilharam conosco suas histórias.

1 Conforme Jesus (2012), reconhecendo-se a diversidade de formas de viver o gênero, dois aspectos cabem na dimensão transgênero, enquanto expressões diferentes da condição: a vivência do gênero como identidade, o que caracteriza transexuais e travestis, ou como funcionalidade, representado por crossdressers, drag queens, drag kings e transformistas. O presente estudo será referente às vivências de gênero identitárias, referindo-se às/aos transexuais e às travestis. 
Resultados e discussão: as trajetórias de mulheres trans nas politicas públicas de saúde

Utilizaremos, como ponto de partida das discussões que serão realizadas em cada um dos eixos, o conceito de tecnologias em saúde, desenvolvido amplamente nas conceituações teóricas de Merhy (1997). Para o autor, além das tecnologias comumente conhecidas no âmbito da saúde, como as máquinas, os equipamentos e os procedimentos cirúrgicos ou diagnósticos (as tecnologias duras), o cuidado em saúde também é constituído por outras duas: as leve-duras e as leves. As tecnologias leve-duras se referem aos saberes estruturados no campo da saúde, como a clínica, a epidemiologia, a psicanálise, entre outras; já as leves são as tecnologias relacionais, que se materializam através do trabalho vivo em ato, nos encontros entre trabalhadores e usuários, mediando, inclusive, o uso das leve-duras e duras (Merhy, 1997). Desse modo, as três tecnologias referidas são utilizadas em todos os tipos de serviço de saúde, ainda que em determinados atendimentos ou encontros de saúde haja primazia pelo uso de uma em detrimento da outra. Nesse sentido, para Merhy, essas tecnologias compõem as “caixas de ferramentas tecnológicas" utilizadas pelos trabalhadores durante a construção dos atos de saúde. Assim, a caixa de ferramentas utilizada pelos profissionais de saúde funciona como uma intermediação entre as possíveis ofertas de cuidado e as demandas dos usuários.

Assim, fazendo uso desses conceitos, no primeiro eixo de discussão discorreremos sobre as tecnologias duras no processo transexualizador e a relação das entrevistadas com a organização desse processo, bem como seu acesso às diferentes biotecnologias que lhes permitem realizar as modificações corporais que desejam. Após, no segundo eixo, será abordada a questão da patologização das identidades trans, momento em que discutiremos a apropriação do discurso científico, compreendido aqui como uma tecnologia leve-dura, acerca da experiência transexual. Por fim, na última categoria, versamos sobre a relação das entrevistadas com os profissionais de saúde, utilizando o conceito das tecnologias leves, quando abordaremos os afetos sentidos nos encontros entre profissionais e usuários, bem como os atos de saúde constituídos através dessa união.

\section{Tecnologias duras: vivências no processo transexualizador}

A referência de cuidado integral à saúde das mulheres trans que entrevistamos, na maioria dos casos, é um hospital que comporta um ambulatório responsável pelos procedimentos referentes ao processo transexualizador ${ }^{2}$ no Rio Grande do Sul. Tal fato nos chama a atenção, visto que as entrevistadas residem em um município de médio porte, localizado no interior do Rio Grande do Sul, de modo que necessitam se deslocar para outra cidade para serem atendidas pelo programa. 0 acesso aos serviços de saúde de base territorial (Atenção Básica), na maioria das vezes, ocorre em razão da necessidade de conseguir um encaminhamento para esse ambulatório, ficando restrito a esses casos. Assim, não há uma maior vinculação delas com as equipes de saúde da Atenção Básica.

Cabe ainda salientar que quatro das seis entrevistadas já realizaram a cirurgia transgenitalizadora, uma delas está passando pelo processo e aguarda a realização da cirurgia, e outra não deseja realizar tal procedimento. Dessa forma, mesmo as entrevistadas que já realizaram a cirurgia há bastante tempo ainda têm como referência de cuidado à saúde o ambulatório transexualizador, principalmente quando o cuidado se refere a questões especificas referentes às modificações corporais próprias do processo de transição. Assim, na maior parte dos relatos, elas referem que se sentem mais seguras ao acessar o serviço especializado, pois isto garantiria melhor preparação por parte dos profissionais em relação ao atendimento das suas demandas específicas.

A pessoa trans, dependendo do espaço, se sente amarrada, porque ela corre grande risco, e não é

\footnotetext{
Esse processo é regulamentado pela Portaria no 2.803/2013, do Ministério da Saúde, que estabelece as diretrizes para a realização dos procedimentos ambulatoriais e cirúrgicos referentes a readequação genital em pessoas transexuais (Brasil, 2013b).
} 
pequeno, de encontrar profissionais que não estão preparados e lá [hospital] é uma área especializada. Eles devem receber treinamento, é diferente, e eu acho que a tendência é acontecer isso em outros lugares. (Larissa)

Desse modo, o motivo da centralização do cuidado se dar no hospital não se refere apenas à questão da cirurgia transgenitalizadora em si, mas é devido à dificuldade que elas enfrentam em encontrar profissionais preparados para atender suas demandas especificas fora do serviço especializado. Foi recorrente, no relato das entrevistadas, a dificuldade de conseguir informações referentes à forma correta de utilização da terapia hormonal, sendo que a maioria só obteve acesso a esse tipo de cuidado após o ingresso no processo transexualizador.

Aqui na minha cidade nenhum médico quis me dar a receita para hormônio, eles não quiseram me dar [...] e quando eu entrei nesse programa, o maravilhoso desse programa é que tu tem toda a assistência que tu precisa. Ali eles fazem a dosagem hormonal e veem o que tu precisa, o que teu corpo precisa... ah, e lá eles viram que eu não tinha a tal da próstata, eles viram que eu tinha ausência da próstata, eu nasci sem próstata, porém nasci com a genitália masculina, daí aconteceu a cirurgia. (Keila)

Assim, as mulheres trans ou travestis que não fazem acompanhamento no processo transexualizador acabam, na maioria das vezes, ficando sem assistência médica continuada, fazendo uso de hormônios por contra própria. Lionço (2009) chama a atenção para o fato de a regulamentação dos processos cirúrgicos referentes às modificações dos caracteres sexuais ser restrita aos casos de transexualidade, pois se compreende que, nesses casos, a cirurgia pode ajudar tais pessoas a restituírem certa "normalidade".

A centralização do cuidado integral das pessoas trans no ambulatório transgenitalizador gera algumas restrições de acesso e prejudica a autonomia dessa população, levando em conta algumas práticas reproduzidas nesse espaço. 0 cuidado prestado nesse ambiente é centralizado nas tecnologias duras, sendo as intervenções realizadas pelos profissionais de saúde sempre direcionadas no sentido de preparar essas mulheres para a cirurgia transgenitalizadora, a principal tecnologia dura em questão.

Dessa forma, há um direcionamento das intervenções realizadas pelos profissionais de saúde para de averiguar se essas pessoas são ou não "verdadeiras transexuais", condição essencial para ter o acesso à cirurgia garantido. Assim, a vinculação estabelecida entre profissionais e usuárias se constrói de forma muito frágil, visto que elas se sentem constantemente avaliadas, ao invés de acolhidas. Nesse sentido, Bento (2006, p. 56) aponta para a existência do que chama de "protocolos invisíveis", que são obrigatoriedades, ou mesmo uma espécie de censura, presentes no discurso de muitos profissionais de saúde, que vão para além dos critérios explicitados no protocolo convencional.

Uma profissional do grupo de terapia disse assim: "vocês sabem que o público que procura vocês é diferente né?" e eu disse "como diferente?" e ela disse "vocês sabem que eles procuram só para sexo, só para diversão", ou seja, é meio que colocar na cabeça do pessoal que eles merecem menos, que não tão ali para disputar o espaço com os iguais, que vão sempre receber o que sobra ou a violência que tem. $\varepsilon$ isso vai machucando, por mais que a gente tenha a consciência que não é, vai ficando a ferida né, porque são pessoas que deviam estar dando a oportunidade do engrandecimento de um grupo e excluem o grupo. Outra vez eu ouvi dessa mesma profissional: "vocês foram muito machos para chegar até aqui", e poxa, você escuta isso de uma pessoa que se diz uma profissional preparada e diz uma coisa dessas, e você pensa "poxa, o que que é que eu vou ouvir fora daqui, né?”. (Dandara)

Dessa forma, os fragmentos que compõem essa espécie de protocolo invisível são "os insultos, os olhares que estão presentes nas enfermarias, nos ambulatórios e que a cada momento lembram ao \à transexual sua condição de diferente, de 'coisa estranha" (Bento, 2006, p. 59). Tais protocolos também se mostram presentes no modo como os profissionais constroem a relação com as pessoas 
que participam deste processo, que é pautada pela hierarquia do saber biomédico em detrimento da construção de uma relação mais horizontal entre usuários e profissionais. Desse modo, há uma primazia da manutenção dos sujeitos no lugar de paciente, no sentido de serem passivos no processo de produção de saúde, o que acaba restringindo sua autonomia, bem como impedindo-os de assumirem o protagonismo que lhes deveria ser destinado. Cabe salientar que é prerrogativa máxima do SUS a participação ativa dos usuários na construção do seu processo de cuidado e saúde.

O grupo não avança, não há espaço de empoderamento, acolhimento, e quando eu falei de direitos, leis, essas coisas, eles disseram que a minha fala era agressiva, porque é como se eu tivesse confrontando os saberes deles, essas coisas. $\varepsilon$ quanto mais eu procuro essa posição saudável no grupo eles tentam diminuir a minha fala. Fora o diagnóstico de borderline que eles colocaram sem ao menos conversar comigo sobre isso. Disseram que o meu pensamento era dissociativo, que eu tinha o afeto irritado, depressão leve, hostil. (Dandara)

Desse modo, a superioridade do saber biomédico é legitimada através do diagnóstico de disforia de gênero e da forma como todo o processo transexualizador é conduzido, pois há uma restrição quanto à participação ativa das pessoas trans nas decisões referentes à dinâmica de funcionamento do ambulatório. Assim, qualquer ato que possa colocar em cheque a supremacia desse saber é prontamente reprimido por meio da reprodução dos já referidos protocolos invisíveis. Nessa direção, Bento (2006) aponta a existência de uma espécie de esperança e medo entre as pessoas que ingressam no processo transexualizador. Esperança por avistar uma possibilidade de conseguirem realizar as modificações corporais que lhe são tão caras e importantes no reconhecimento e afirmação da sua inteligibilidade social, e medo ao não saberem se conseguirão ou quando terão acesso à cirurgia.

Nesse sentido, a terapia em grupo, também regulamentada pela Portaria $n^{0}$ 2.803/2013 (Brasil, 2013b), é um instrumento comumente utilizado para controlar e normatizar a conduta dos(as) usuários(as) do ambulatório. A terapia, conforme as diretrizes da portaria já referida, deve ter o tempo mínimo de duração de dois anos, sendo que a participação quinzenal das usuárias é condição sine qua non para ter o acesso à cirurgia garantido. Assim, ela passa a ser mais um instrumento tecnológico duro a ser utilizado na seleção do(a) "verdadeiro(a) transexual”, apto a realizar a cirurgia, sendo, de certo modo, utilizada como uma forma de governo e seleção dos(as) usuários(as).

Quando eu entrei era um grupo aberto, onde nesse grupo assinava e colocava o número do prontuário. Era necessário assinar senão não contaria, entre aspas, uma presença, e nisso, fora do grupo, precisava ir todo mês, ou de dois em dois meses com a psicóloga e com consulta esporádica com o urologista que ia fazer a cirurgia na gente [...] voltando à questão da cirurgia, na época que eu entrei, era no mínimo dois anos de acompanhamento, no mínimo do mínimo, só que dentro desses dois anos era necessária uma presença no grupo, ou seja, uma participação por mês, então eu conseguia me descolar da minha cidade para Porto Alegre uma vez por mês [...] só que de 2005 à 2006 veio uma nova regra para o grupo, que precisava ser duas vezes ao mês, quinzenalmente, porém eu não conseguia ir [...] era táxi, era passagem de ônibus e eu não tinha condição financeira, e às vezes eu não conseguia pelo SUS, então teve muito tempo que eu consegui ir uma vez por mês, então aquele tempo virou mais um ano, então no caso o que poderia ser dois anos se transformou em três, em razão da regra ter sido reformulada. Hoje eu sei que foi muito válido, mas foi um tempo assim, angustiante, eu derramei muita lágrima. (Bruna)

Dessa forma, o espaço da terapia de grupo acaba ganhando contornos duros e rígidos, tendo em vista o caráter compulsório que esse instrumento assume no processo. Cabe lembrar que os profissionais que coordenam o grupo são os responsáveis pela suposta "fiscalização" da assiduidade das candidatas. Assim, eles acabam ocupando uma posição policialesca no grupo, o que interfere na vinculação das usuárias com eles, bem como no caráter terapêutico desse instrumento. Diante disso, o caráter regulatório 
desse dispositivo torna-se o real motivo pelo qual muitas delas participam do grupo, em detrimento do caráter terapêutico que o espaço deveria assumir. Desse modo, a terapia passa a atuar como uma tecnologia dura, como mais um procedimento a ser realizado para que se possa ter o acesso à cirurgia garantido. Todavia, temos claro que tal espaço também comporta um caráter terapêutico, visto que possibilita o compartilhamento das vivências entre as participantes do grupo.

Outro ponto que aparece com frequência no relato das entrevistadas diz respeito à falta de clareza nas informações repassadas sobre a forma como o processo de seleção para a cirurgia ocorre efetivamente, bem como sobre detalhes específicos do procedimento. Desse modo, apesar de todo o cuidado produzido no ambulatório ser voltado no sentido de prepará-las para o momento da cirurgia, as informações referentes a esse processo são seletivas, não havendo clareza quanto aos critérios de seleção, bem como o período que elas devem esperar até ter acesso à tecnologia garantido. As informações sobre o procedimento em si não são de todo claras, visto que as usuárias necessitam, muitas vezes, buscar outros meios de conseguir informações sobre a cirurgia e o processo pós-operatório. Desse modo, atualiza-se, novamente, a posição médico-paciente, na qual o paciente ocupa uma posição passiva em seu processo de cuidado, sendo mero objeto das intervenções dos profissionais da saúde.

Lá no ambulatório a relação era bem afastada, e eu não gostava no início, porque no início era assim, eu tinha medo até de falar, era uma coisa que eu ficava assim [...] era muito distanciamento, tipo, você é doente, eu sou profissional, aquela coisa muito distante [...] e eu tava lá porque eu queria fazer a cirurgia, eu não tinha noção nenhuma dos meus direitos, enfim, tu internaliza a questão do "ser abjeto", então tu te limita assim. (Larissa)

Tendo em vista tais apontamentos, percebe-se que a maior parte das queixas das entrevistadas não se refere à falta de conhecimentos tecnológicos referentes ao processo transexualizador em si, mas à falta de acolhimento e da construção de uma relação mais próxima com os trabalhadores de saúde envolvidos. Como aponta Merhy (1998, p. 105), assim como outros usuários do SUS, elas se sentem "inseguras, desinformadas, desamparadas, desrespeitas" em muitos momentos desse processo. Desse modo, apesar do respaldo tecnoassistencial dado pelo hospital, no que concerne à cirurgia em si e aos outros procedimentos de modificação corporal realizados nesse espaço, encontramos uma falha na comunicação e na vinculação das usuárias com os profissionais de saúde. Assim, os atos de saúde produzidos pelo processo transexualizador são, na maioria das vezes, centrados nos procedimentos ao invés das pessoas que usam o serviço, perdendo-se a real dimensão do cuidado em saúde: a ampliação da autonomia dos modos de andar na vida dos sujeitos (Merhy, 1998).

\section{Tecnologias leve-duras: discursos que (de)formam vidas}

Conforme Merhy (1997), as tecnologias leve-duras se referem aos saberes estruturados e definidos que permitem ao trabalhador de saúde olhar e compreender o usuário a partir de um ponto de vista. Elas são consideradas leves e duras porque se constroem a partir da mediação entre a dureza e a leveza que constituem os atos de saúde. Assim, são duras por se tratar de um saber construído a priori, antes do encontro com o usuário, e leves por ser necessário um olhar singular para cada situação que se apresenta, pois é somente através do encontro com o usuário de saúde, do trabalho vivo em ato, que poderemos construir uma forma de cuidado que leve em conta os saberes estruturados pela saúde e as especificidades de cada caso (Merhy, 1997). No que se refere à transexualidade, o campo da saúde tem um olhar estruturado acerca dessa experiência, por intermédio do qual a maior parte das intervenções dos profissionais da saúde são construídas.

Segundo Amaral (2007), em 1980, a transexualidade passou a agregar o rol de patologias e transtornos descritos no Diagnostic and Statistical Manual of Mental Disorders (DSM) III, tendo, desse modo, o seu lugar garantido nos discursos médicos e psiquiátricos. Ao longo dos anos, com a revisão periódica que é própria da história do DSM, o termo transexualismo foi substituído por transtorno de 
identidade de gênero (TIG), passando a ser descrito como um "estado psicológico no qual a identidade de gênero está em desacordo com o sexo biológico" (Amaral, 2007, p. 37). Já na revisão que ocorreu em 2013, e que culminou no lançamento do DSM V, o TIG passou a se configurar como disforia de gênero e, embora essa caracterização seja mais descritiva, no sentido de abarcar questões mais complexas em relação à transexualidade, ainda possui forte caráter patologizante, visto que a disforia é vista “como um problema clínico, e não como identidade por si própria” (APA, 2014, p. 492). Segundo Bento (2011), é importante ressaltar a importância que o DSM tem mundialmente, visto que suas diretrizes norteiam a prática de diversos profissionais da saúde de várias partes do mundo, o que elucida de maneira evidente o poder geopolítico desse manual. A autora ainda aponta que não é possível ignorar a dimensão e a influência que o DSM tem sobre a construção do entendimento que se faz sobre a transexualidade, visto que, em diversos países, é o manual que embasa a criação e o desenvolvimento de políticas públicas direcionadas à população trans.

Destarte, a apropriação da transexualidade pelo discurso biomédico incide diretamente na vida das pessoas que vivenciam a transexualidade, bem como nas relações que elas desenvolvem com os profissionais de saúde. As entrevistadas referiram não reconhecer a sua existência e a forma como vivenciam o seu gênero como uma experiência patológica, contrariando as explicações acerca da transexualidade construídas pelo saber biomédico. Para elas, o maior problema se encontra na forma como as outras pessoas entendem essa vivência e na falta de compreensão das pessoas cisgênero, ${ }^{3}$ inclusive os profissionais de saúde que as atendem, sobre as suas necessidades específicas.

Dessa forma, a discussão sobre a despatologização das identidades trans é demasiadamente complexa, pois não se trata apenas do âmbito da saúde, mas também do campo ético e político, tendo em vista que "a discussão sobre gênero é um espaço de luta marcado por interesses múltiplos" (Bento, 2006, p. 19). Conforme Butler (2009), se, por um lado, é por intermédio do diagnóstico que as pessoas trans conseguem ter acesso às ferramentas necessárias para a realização da sua transição, o que pode ser um fator crucial para aumentar a autonomia dessa população, por outro, o diagnóstico faz várias pressuposições que comprometem essa mesma autonomia. Para a autora, o diagnóstico reforça a ideia de que as normas de gênero não foram assimiladas adequadamente por essas pessoas, o que indica que, de alguma forma, ocorreu uma falha ou um erro durante esse processo. Ele pode também reforçar a ideia de que as pessoas trans são acometidas por algo que elas não entendem, concebendo-as como pessoas sem a capacidade de falar sobre sua própria experiência ou de escolher sozinhas o que é melhor para o seu próprio corpo.

Enfim, ébem complicada essa questão e sempre que eu vejo gente falando transexualismo eu sempre digo: "Tá e a gente não vai falar do cissexualismo?", porque as pessoas cis são elas que são doentes, não somos nós, são elas que nos colocam como doentes, são elas que nos jogam para a margem, para a abjeção, são elas que nos matam com 35 anos de idade, são elas que nos colocam em depressão e por isso que nós tentamos nos matar quatro vezes mais que a média da população em geral, e eu acredito que a patologização é uma das coisas que ajuda nisso, porque ela não nos coloca como os "normais", as pessoas normais, ela nos coloca como os doentes, que precisam de um atestadinho para garantir todos os seus direitos e do aval de uma pessoa cisgênera para fazer toda e qualquer coisa. (Laerte)

Nesse sentido, o diagnóstico se mostra um instrumento perverso, pois é somente a partir dele que as pessoas que vivem a transexualidade passam a ter a sua vida e a sua experiência legitimada, necessitando do reconhecimento do outro, a partir de uma perspectiva patologizante, para terem os seus direitos assegurados e garantidos. Desse modo, elas precisam aprender a se apresentar por

\footnotetext{
30 termo cisgênero é utilizado para se referir às pessoas cujo gênero é o mesmo que o designado em seu nascimento. Isto é, configura uma concordância entre a identidade de gênero de um indivíduo com o gênero associado ao seu sexo biológico e/ou designação social.
} 
meio de um discurso que não é seu e que as apaga enquanto protagonistas de sua própria história, buscando as enquadrar em rígidos critérios de seleção, deslegitimando a complexa singularidade presente em cada vida humana (Butler, 2009). Em vista disso, a patologização das identidades trans, produzida pelos discursos da saúde, acaba por afastar tal população dos serviços de saúde e esse afastamento é decorrente do abismo entre o discurso biomédico e a experiência de vida dessas pessoas, que não compreendem sua existência como patológica.

Dessa forma, para Butler (2009, p. 113), "se apresentar num discurso que não é o seu - um discurso que apaga você no ato de representar você -, num discurso que exclui a linguagem que poderia preferir usar na descrição de quem você é" é a única forma das pessoas trans assegurarem o seu direito de acesso às biotecnologias necessárias para a realização do processo transexualizador. Nesse sentido, a patologização pode direcionar o olhar dos profissionais de saúde, fazendo-os compreender todas as manifestações de vida das pessoas trans através da ótica da doença. Assim, a capacidade de compreensão acerca das singularidades existentes em cada uma das pessoas que vivenciam a experiência transexual é restringida, o que leva os profissionais a categorizar grande parte dos comportamentos dessa população como sendo de ordem patológica.

A primeira coisa quando você chega lá e apresenta algum estado de depressão, alguma coisa, a única coisa que eles sabem fazer é aplicar a medicação, um antidepressivo, eles não procuram saber a fonte, qual é a motivação, e ao invés de tratar aquilo, eles acham que só com a medicação resolve e eu já questionei eles por isso. Ontem no grupo eu falei: como é que eu vou confiar numa avaliação psiquiátrica se até a TPM virou transtorno mental agora? Como é que eu vou aceitar que uma condição de vida natural agora virou transtorno, vai fazer o que, receitar agora algo para que elas não menstruem para que elas não tenham o transtorno mental? $\varepsilon$ eles não compreendem isso, eles não conseguem compreender, porque é a ciência deles, o saber deles, e eles acham que o saber deles tá acima de tudo. (Dandara)
Segundo Bento e Pelucio (2012), o processo de patologizar as identidades trans não garantiu nenhum direito de fato a essa população, pois apenas colaborou para que a transexualidade fosse compreendida pelo viés da lógica médica e concebida, desse modo, como passível de ser catalogada, mensurável e até mesmo curável. Sabese que o diagnóstico faz várias pressuposições que comprometem a autonomia dessa população (Butler, 2009), no sentido de afirmar que tais pessoas não podem decidir sozinhas sobre a realização dos procedimentos relativos ao processo de transição de gênero, deixando aos profissionais de saúde o aval da decisão. Tais condições impostas se referem a um "tutelamento dos corpos e subjetividades" (Bento; Pelucio, 2012, p. 574) dessas pessoas, desautorizandoas a falarem sobre aquilo que estão vivendo a partir de suas próprias vivências e percepções, outorgando somente aos discursos ditos científicos o caráter de legitimidade sobre essa experiência (Bento; Pelucio, 2012).

Desse modo, a partir da contextualização realizada, torna-se claro que a apropriação do discurso da saúde em relação à experiência transexual é uma construção histórica, que teve como intuito classificar as experiências consideradas normais e anormais em relação ao gênero. Para Feuerwerker (2014), a patologização dos modos de vida que diferem da norma preestabelecida é muito grave e deve ser discutida com cuidado, pois pode desqualificar essas pessoas para a vida, e até mesmo restringir sua liberdade e autonomia. No caso da população trans, essa restrição de liberdade e autonomia é somada à restrição de cidadania, dadas as barreiras de acesso às diversas políticas públicas que elas já enfrentam cotidianamente.

\section{Tecnologias leves: entre encontros e desencontros}

Ao nos encontramos com usuários dos serviços de saúde, somos afetados, assim como afetamos aquele a quem dirigimos nosso cuidado. Essa capacidade de afetar-se e afetar o outro através de um encontro diz respeito às transformações, inquietações, sentimentos e reflexões que possam nascer dessa união. Para Espinosa, esses afetos podem ser de duas ordens: tristes e alegres (Deleuze, 2002). 
Os tristes são aqueles que diminuem nossa potência de agir, nos paralisam e nos desvitalizam; e os alegres são aqueles que aumentam a nossa potência de agir, nos preenchem de vida e de possibilidades, expandindo nossos modos de existir. Dessa forma, os atos de saúde podem ser preenchidos tanto de afetos alegres como de tristes, podendo expandir as possibilidades de cuidados de cada usuária e usuário, bem como reproduzir os preconceitos e discriminações comumente presentes em nossa sociedade (Merhy; Feuerwerker, 2009).

Em vista disso, as entrevistadas experienciaram diferentes (des)encontros com os profissionais de saúde, sendo que alguns foram preenchidos de afetos alegres, auxiliando-as na expansão da sua autonomia e nos seus modos de andar na vida, e outros repletos de afetos tristes, que se materializam através de preconceitos e discursos heteronormativos de exclusão e discriminação.

Mas assim, em relação aos serviços de saúde eu não tenho boas lembranças, nem posso dizer que são maravilhosos, porque eu sempre fui violada dentro desses espaços, sempre tive meus direitos violados, sempre fui tratada como uma coisa, uma aberração dentro desses espaços. Nunca tive um olhar humanizado dessas pessoas para mim, e eu não sei se é porque eu sou trans ou se é de praxe essas pessoas fazerem essas coisas aos outros, isso realmente me choca. (Laerte)

Nessa direção, cabe lembrar que a política de saúde da população LGBT possui como prerrogativa a construção de um SUS com maior equidade que, para isso, tem como um de seus objetivos a implantação de ações que visem extinguir a discriminação e o preconceito nos espaços e no atendimento prestado nos serviços públicos de saúde. Ela compreende que os efeitos da discriminação e do preconceito incidem de maneira muito intensa nos processos de saúde/ doença, com suas diretrizes e objetivos voltados para "mudanças na determinação social da saúde, com vistas à redução das desigualdades relacionadas à saúde destes grupos sociais" (Brasil, 2013a, p. 8).

No âmbito das questões referentes à saúde da população trans especificamente, o texto da política traz apontamentos de grande relevância para que haja uma mudança no modo como o cuidado é prestado a esse grupo atualmente. Entre as recomendações estão: o aprimoramento do processo transexualizador, bem como a sua universalização; a garantia de uso do nome social nos serviços de saúde pública e nos documentos e formulários relativos ao SUS; investimento em pesquisas que tragam avanços tecnológicos e terapêuticos a essa população; uso de banheiros e enfermarias que sejam correspondentes à identidade de gênero da pessoa; inclusão dos campos "identidade de gênero" e "orientação sexual” nos formulários e prontuários e sistemas do SUS; e o acompanhamento no uso e no tratamento de possíveis agravos em saúde decorrentes da hormonioterapia e da utilização de próteses de silicone.

Conforme Paiva e Félix-Silva (2014), tais mudanças são de extrema importância para o reconhecimento da cidadania dessa população, bem como para a consolidação de um cuidado para além das doenças, havendo preocupação com a promoção de saúde e as complexidades intrínsecas a esse processo. Contudo, apesar da necessidade e da importância que as mudanças nas políticas públicas representam, elas por si só não são suficientes, visto que a maior mudança se encontra no cotidiano dos serviços de saúde. É necessário que os trabalhadores do SUS estejam preparados para atender e receber tais demandas, tendo o total cuidado para não reproduzir o preconceito e a discriminação que acomete tal população no cotidiano de seus trajetos pessoais.

Atualmente eu tenho uma vinculação com a agente de saúde do meu bairro. Muito querida, falei para ela da transexualidade, e ela foi super de boa. Maso retorno dela foi "não estamos preparados, não temos controle nenhum, não existe uma política pública interna, regional e municipal que faça o atendimento das pessoas trans". Só tem o serviço que trabalha com a questão do HIV e das DSTs, mas daí tem a crítica né, que a população trans é sempre ligada a este tipo de cuidado, é uma forma de nos encaixotar né. [...] Mas aqui não tem, nem política de nome social, diz que tem, mas aqui não tem. (Larissa)

Cabe ainda salientar que o distanciamento das pessoas trans dos serviços de saúde se deve, 
em grande parte das vezes, ao receio de sofrer algum tipo de ato discriminatório por parte dos profissionais de saúde, bem como à fragilidade que há na constituição de vínculos entre essa população e os serviços de saúde de referência territorial. Essa fragilização pode ser percebida no relato das entrevistadas, principalmente quando elas se referem ao ambulatório transexualizador como referência de cuidado e não a atenção básica do seu território. Desse modo, tal distanciamento contribui para a marginalização dessa população, o que leva essas pessoas a terem suas histórias escondidas sob o véu do anonimato e da invisibilidade, prejudicando a construção de linhas de cuidado que convirjam de maneira genuína para as demandas específicas desse grupo populacional (Tagliamento, 2015). Assim, o que mais aparece nas narrativas das entrevistadas, em relação a suas experiências com os serviços de saúde, é o fato delas evitarem frequentar tais espaços por receio de sofrerem algum ato discriminatório:

Não acessei nenhum serviço de atenção básica antes de retificar meus documentos, eu tive a sorte de não passar por isso, sabe, eu tive a sorte de não ficar doente, de não precisar de uma consulta, por incrivel que pareça, e eu meio que evitava. [...]. E ficou um pouco essa questão, porque hoje para eu ir no médico é muito difícil, porque eu me acostumei tanto a evitar essa questão de SUS, de constrangimento, de chamarem o meu nome antigo, que hoje em dia eu posso tá um pouco doente, ou sei lá, eu para ir no médico é muito raro, então ficou isso. $\varepsilon$ a trans faz muito isso, ela se automedica, porque é menos um sofrimento para ela passar. A trans não quer ser chamada no SUS pelo nome masculino, ou ficar tensa se vão chamar pelo nome social, porque o nome social ele tá junto, mas ele não entra na frente do nome de registro, então a pessoa pode tá ali e ter o nome social, mas se equivocar e chamar o nome de registro... (Bruna)

Assim, há uma despotencialização nesses encontros entre as entrevistadas e os profissionais de saúde, pois o cuidado ofertado, como aponta Feuerwerker (2014, p. 58), funcionou "como barreira para produção de vida”. Por esse motivo, como aponta Simpson (2015), é comum as pessoas trans e travestis fazerem uso de medicação por conta própria, tendo em vista as diversas dificuldades de acesso e acolhimento que elas encontram nos cotidianos dos serviços de saúde.

Segundo Feuerwerker (2014, p. 27), deveríamos, ao produzir cuidado em saúde, caminhar no sentido de auxiliar os usuários e usuárias a ampliar sua capacidade, sua "autonomia nos seus modos de andar na vida”, pois essa expansão de autonomia seria o que a autora compreende, em última instância, como saúde. Assim, é necessário ampliar o olhar e a escuta, permitindo que a complexidade da vida das pessoas trans invada as unidades de saúde, ampliando a forma como os profissionais desses locais enxergam a experiência transexual. Isso implica colocar esses usuários em um outro lugar, em uma nova posição: "a de agente ativo na produção de sua saúde e no encontro com os trabalhadores de saúde" (Feuerwerker, 2014, p. 6o). Encontros permeados por esses princípios tornam-se importantes vias de afirmação e empoderamento para as pessoas trans, conforme relato de uma das entrevistadas:

Teve um período que eu estava sendo acompanhada por um médico clínico da atenção básica de Porto Alegre e ele me disse assim: "olhe, eu não sei muito bem da sua situação, não conheço, mas eu vou ficar a par e a gente vai conversando" e ele disse uma coisa que a té hoje eu nunca ouvi lá no ambulatório "se precisar de qualquer coisa, bata aqui na porta, vocênão precisa ir lá no balcão, bata aqui na porta e fale comigo" e isso eu não ouvi lá no hospital, esse acolhimento, $e$ isso me surpreendeu e nesse tempo eu fiquei em acompanhamento com ele, e ele me acompanhou desde 2014 até ele se aposentar, ano passado, e nesse período ele orientava a questão da medicação, dos hormônios. Eu tinha um diálogo mais aberto com ele que dentro do próprio ambulatório transexualizador. (Dandara)

Cabe, ainda, salientar que se afirma na Carta dos Direitos dos Usuários dos Serviços de Saúde documento lançado pelo Ministério da Saúde em 2009 - que todo cidadão brasileiro "tem direito ao atendimento humanizado, acolhedor e livre de qualquer discriminação" (Brasil, 2011, p. 3), bem como de receber um atendimento que respeita 
"a sua pessoa, seus valores e seus direitos" (Brasil, 2011, p. 4). Desse modo, é dever de todo trabalhador do SUS garantir que tais diretrizes sejam colocadas em prática, correndo o risco de receber sansões jurídicas caso desrespeite ou reproduza ato discriminatório em relação a usuário, seja qual for o caráter da sua demanda de cuidado. Diante disso, fazem-se urgentes discussões sobre identidade de gênero no cotidiano dos serviços de saúde, visando colocar efetivamente em prática o que a Política Nacional de Saúde LGBT já preconiza em seu texto.

\section{Considerações finais}

Neste trabalho, buscou-se conhecer os caminhos percorridos pelas pessoas trans nas políticas públicas de saúde, visto que esses itinerários ainda são poucos visibilizados, o que prejudica a construção de linhas de cuidado que tenham convergência com as reais necessidades desse segmento populacional. Como resultado, encontramos maior aproximação dessa população com os serviços especializados, que realizam a cirurgia transgenitalizadora, em detrimento dos serviços da atenção básica. Isso se justifica, em grande parte, pela dificuldade de encontrar profissionais que estejam preparados para atender as demandas específicas da população trans. Tal situação mostra que as questões referentes ao gênero ainda são pouco abordadas na formação dos profissionais de saúde e, quando abordadas, são restritas ao diagnóstico de disforia de gênero, havendo certa distância entre o conhecimento acadêmico e as necessidades reais vivenciadas pelas pessoas trans.

Desse modo, compreendemos que é necessário que os saberes advindos do campo da saúde estejam a serviço da produção de maior autonomia das pessoas trans, para auxiliá-las a ampliar e expandir suas possibilidades de vida. Assim, compreendemos que o conhecimento produzido no campo da saúde é de extrema importância na vida da população trans, pois permite a realização de procedimentos referentes à transição de gênero, o que é de extrema importância no processo de construção da inteligibilidade social dessas pessoas. Em vista disso, não se exclui a importância desses saberes, mas aponta-se a necessidade de construir uma interlocução entre a produção de conhecimento científico sobre a transexualidade e as experiências de vida das pessoas trans.

A articulação de ações de educação permanente em saúde são de extrema importância na ampliação do aparato conceitual dos profissionais de saúde, no sentido de prepará-los para receberem e atenderem a população trans em suas especificidades, seja na ampliação das tecnologias leves para acolher tais sujeitos em sua singularidade, com uma atitude livre de discriminação e preconceito, seja atendendo as necessidades referentes ao uso das tecnologias duras, que dizem respeito às modificações corporais reivindicadas por essa população, como a terapia hormonal e a cirurgia transgenitalizadora. Por isso, consideramos necessária uma maior articulação dos serviços especializados com a atenção básica e com os profissionais agentes comunitários de saúde, pois são eles que, mesmo desconhecendo a realidade e as políticas voltadas a essas pessoas, estão em contato com elas, em seu território. Produzir saúde, portanto, é produzir subjetividades, é produzir e garantir modos diversos de ser e estar no mundo, visibilizando, cada vez mais, as trajetórias dessas mulheres trans e garantindo o seu acesso às políticas de saúde e à cidadania ativa.

\section{Referências}

\section{AMARAL, D. M. A psiquiatrização da}

transexualidade: análise dos efeitos do diagnóstico de transtorno de identidade de gênero nas práticas de saúde. 2007. Dissertação (Mestrado em Saúde Coletiva) - Universidade do Estado do Rio de Janeiro, Rio de Janeiro, 2007.

APA - AMERICAN PSYCHIATRIC ASSOCIATION. DSM-5: manual diagnóstico e estatístico de transtornos mentais. 5. ed. Porto Alegre:

Artmed, 2014.

BENTO, B. A reinvenção do corpo: sexualidade e gênero na experiência transexual. Rio de Janeiro: Garamond, 2006. 
BENTO, B. Luta globalizada pelo fim do diagnóstico de gênero. In: SANTOS, L. H. S.; RIBEIRO, P. R. C. (Org.). Corpo, gênero e sexualidade: instâncias e práticas de produção nas políticas da própria vida. Rio Grande: Furg, 2011. p. 89-108.

BENTO, B.; PELUCIO, L. Despatologização do gênero: a politização das identidades abjetas. Revista de Estudos Feministas, Florianópolis, v. 20, n. 2, p. 569-581, 2012.

BRASIL. Ministério da Saúde. Carta dos direitos dos usuários da saúde. Brasília, DF, 2011.

BRASIL. Ministério da Saúde. Política nacional de saúde integral de lésbicas, gays, bissexuais, travestis e transexuais. Brasília, DF, 2013a.

BRASIL. Portaria $\mathrm{n}^{0} 2.803$, de 19 de novembro de 2013. Redefine e amplia o processo transexualizador no Sistema Único de Saúde (SUS). Diário Oficial da União, Brasília, DF, 21 nov. 2013 b.

BUTLER, J. Desdiagnosticando o gênero. Physis, Rio de Janeiro, v. 19, n. 1, p. 95-126, 2009.

DELEUZE, G. Espinosa: filosofia prática. São Paulo: Escuta, 2002.

FERIGATO, H. S.; CARVALHO, S. R. Pesquisa qualitativa, cartografia e saúde: conexões. Interface: Comunicação, Saúde, Educação, Botucatu, v. 15, n. 38, p. 663-675, 2011.

FEUERWERKER, L. C. M. Micropolítica e saúde: produção do cuidado, gestão e formação. Porto Alegre: Rede Unida, 2014.

JESUS, J. G. Orientações sobre identidade de gênero: conceitos e termos. 2. ed. Brasília, DF, 2012.

JOVCHELOVITCH, S.; BAUER, M. W. Entrevista narrativa. In: BAUER, M. W.; GASKELL, G. (Ed.). Pesquisa qualitativa com texto, imagem e som: um manual prático. 2. ed. Petrópolis: Vozes, 2003. p. 9o-113.

LIONÇO, T. Atenção integral à saúde e diversidade sexual no processo transexualizador do SUS: avanços, impasses, desafios. Physis, Rio de Janeiro, v. 19, n. 1, p. 43-63, 2009.
MERHY, E. E. Em busca do tempo perdido: a micropolítica do trabalho vivo em saúde. In: MERHY, E. E.; ONOCKO, R. (Org.). Agir em saúde: um desafio para o público. São Paulo: Hucitec, 1997. p. 71-112.

MERHY, E. E. A perda da dimensão cuidado na produção da saúde: uma discussão do modelo assistencial e da intervenção no seu modo de trabalhar a assistência. In: CAMPOS, C. R. (Org.). Sistema Único de Saúde em Belo Horizonte: reescrevendo o público. São Paulo: Xamã, 1998. p. 103-120.

MERHY, E. E. Saúde e direitos: tensões de um SUS em disputa, molecularidades. Saúde e Sociedade, São Paulo, v. 21, n. 2, p. 267-279, 2012.

MERHY, E. E.; FEUERWERKER, L. C. M. Novo olhar sobre as tecnologias de saúde: uma necessidade contemporânea. In: MANDARINO, A. C. S.; GOMBERG, E. (Org.). Leituras de novas tecnologias e saúde. Salvador: Edufba, 2009. p. 29-56

PAIVA, A. L. S.; FÉLIX-SILVA, A. V. Produção protética dos corpos: experiências trans e políticas de saúde. Ártemis, Campina Grande, v. 18, n. 1, p. 551-563, 2014.

SIMPSON, K. Transexualidade e travestilidade na saúde. In: BRASIL. Ministério da Saúde. Transexualidade e travestilidade na saúde. Brasília, DF, 2015. p. 9-16.

TAGLIAMENTO, G. Direitos humanos e a saúde: a efetivação de políticas públicas voltadas à saúde integral da população trans. In: BRASIL. Ministério da Saúde. Transexualidade e travestilidade na saúde. Brasília, DF, 2015. p. 65-8o.

VINUTO, J. A amostragem em bola de neve na pesquisa qualitativa: um debate em aberto. Temáticas, Campinas, v. 22, n. 44, p. 203-220, 2014.

\section{Contribuição dos autores}

Ambos os autores analisaram e interpretaram os dados, redigiram o artigo e o revisaram criticamente, ainda aprovando a versão a ser publicada.

Recebido: 10/12/2017

Aprovado: 02/10/2019 